\title{
Silagens e fenos em associação à palma forrageira para vacas em lactação. Consumo, digestibilidade e desempenho
}

\author{
Silages and hays in association with spineless cactus for lactating cows. Intake, \\ digestibility and performance
}

\author{
WANDERLEY, Walmir Lima ${ }^{1}$; FERREIRA, Marcelo de Andrade ${ }^{2} *$; BATISTA, \\ Ângela Maria Vieira ${ }^{2}$; VÉRAS, Antonia Sherlânea Chaves ${ }^{2}$ : SANTOS, Djalma \\ Cordeiro dos ${ }^{3}$; URBANO, Stela $\mathrm{Antas}^{4}$; BISPO, Safira Valença ${ }^{5}$
}

\author{
${ }^{1}$ Instituto Federal de Pernambuco, Campus Barreiros, Barreiros,Pernambuco, Brasil. \\ ${ }^{2}$ Universidade Federal Rural de Pernambuco, Departamento de Zootecnia, Recife, Pernambuco, Brasil. \\ ${ }^{3}$ Instituto Agronômico de Pernambuco, Arcoverde, Pernambuco, Brasil. \\ ${ }^{4}$ Programa de Doutorado Integrado em Zootecnia da UFRPE/UFPB/UFC, Areia, Paraíba, Brasil. \\ ${ }^{5}$ Universidade Federal da Paraíba, Centro de Ciências Agrárias, Departamento de Zootecnia, Areia, \\ Paraíba, Brasil. \\ *Endereço para correspondência: ferreira@dz.ufrpe.br
}

\section{RESUMO}

Objetivou-se avaliar o efeito da associação de silagens de girassol e sorgo; fenos de leucena, guandu e capim-elefante, com palma forrageira sobre a produção e composição do leite; consumo e digestibilidade aparente dos nutrientes em vacas 5/8 Holandês-zebu. Foram utilizadas cinco vacas, com peso corporal médio e produção de leite média diária de $516,95( \pm 5,58)$ e $11,1( \pm 0,75) \mathrm{kg}$, respectivamente. Os consumos de matéria seca, matéria orgânica, proteína bruta, carboidratos totais e carboidratos não fibrosos, produção de leite em $\mathrm{kg} / \mathrm{dia}$, os teores e as produções, em $\mathrm{kg} /$ dia, de gordura, proteína e sólidos totais do leite e a digestibilidade da proteína bruta e carboidratos não fibrosos não foram influenciados pela associação das silagens e fenos com a palma forrageira. $\mathrm{O}$ consumo de extrato etéreo, produção de leite corrigida e a eficiência alimentar foram superiores no tratamento com silagem de girassol em relação aos fenos. O consumo de fibra em detergente neutro foi superior para o tratamento com feno de capim-elefante, em relação à silagem de girassol. A silagem de girassol proporcionou maior produção de leite, corrigida para gordura e melhor eficiência alimentar, quando comparada aos fenos.

Palavras-chave: carboidrato não fibroso, energia, Opuntia fícus indica, produção de leite, proteína, volumoso.

\section{SUMMARY}

The aim of the present experiment was to assess the effect of the association of the spineless cactus with sunflower silage, sorghum silage, leucena hay, pigeon pea hay or elephant grass hay on intake, apparent digestibility of nutrients and milk yield and composition in crossbred lactating cows. Five cows with average body weight and daily milk yield of 516.1 and $11.1 \mathrm{~kg}$, respectively. The intakes of dry matter, organic matter, crude protein, total carbohydrates and non-fibrous carbohydrates, milk yield, contents and yield ( $\mathrm{kg} /$ day) of fat, protein and total solids of milk and digestibility of crude protein and non-fibrous carbohydrates were not influenced by the combination of the silage and hay with cactus. The ether extract intake, fat-corrected milk yield and feed efficiency were higher to treatment with sunflower silage compared to hays. The neutral detergent fiber intake was higher in the treatment with elephant grass hay compared to sunflower silage. Sunflower silage produced higher fatcorrected milk and better feed efficiency when compared to hay.

Keywords: energy, milk yield, non-fibrous carbohydrates, protein, Opuntia fícus indica, roughage. 


\section{INTRODUÇÃOO}

A pecuária leiteira do nordeste brasileiro caracteriza-se por envolver grande número de pequenos e médios produtores. Todavia, as condições climáticas, ocasionadas pelas secas periódicas de maior ou menor intensidade, afetam diretamente a potencialidade pecuária da região, devido, principalmente, à menor quantidade e qualidade de forragens.

Uma das restrições mais importantes em sistemas de produção, nas regiões tropicais, é a subnutrição, devido à limitação, não só em quantidade, bem como a qualidade da forragem disponível (MENDIETA-ARAICA et al., 2011). As características climáticas do nordeste brasileiro afetam diretamente a potencialidade pecuária da região. Nesse sentido, na época seca, ocorre queda na disponibilidade e qualidade da forragem, devido à escassez e irregularidade de chuvas, associadas à altas temperaturas, o que diminui a lucratividade do setor, seja por menor produção de leite, seja no aumento do fornecimento de alimento concentrado para atendimento das exigências animais.

No Agreste e Sertão de Pernambuco, a palma forrageira (Opuntia fícus-indica Mill e Nopalea cochenillifera SalmDyck), em virtude de ser adaptada às condições edafo-climáticas e apresentar altas produções de matéria seca por unidade de área, altos teores de carboidratos não fibrosos (CNF) e elevado coeficiente de digestibilidade da matéria seca, é comumente utilizada como base da alimentação do rebanho leiteiro, durante o período de pouca disponibilidade de forragem (FERREIRA et al., 2009).

A palma forrageira, por possuir baixa concentração de matéria seca e fibra em detergente neutro (BATISTA et al.,
2003), quando utilizada como volumoso exclusivo, pode provocar diminuição da ruminação e do teor de gordura do leite, perda de peso e diarreia (ANDRADE et al. 2002; SOSA et al. 2004). Entretanto, a simples associação com fontes de fibra, fisicamente efetiva, provoca maior mastigação e ruminação, de modo a garantir as condições normais de rúmen, produção de gordura do leite e ruminação satisfatórios, o que não torna observável perda de peso ou diarreias nos animais (FERREIRA et al., 2009).

Objetivou-se avaliar o efeito das silagens de sorgo e girassol e os fenos de leucena, feijão guandu e capim-elefante, como fontes de fibra, em associação com a palma forrageira em dietas, para vacas em lactação, sobre a produção e composição do leite, consumo e digestibilidade aparente dos nutrientes.

\section{MATERIAL E MÉTODOS}

$\mathrm{O}$ experimento foi realizado na Estação Experimental de Arcoverde-PE, pertencente ao Instituto Agronômico de Pernambuco - IPA. Foram utilizadas cinco vacas 5/8 Holandês-zebu, com peso vivo médio de 516,95 $( \pm 5,58)$, produção de leite de $11,1( \pm 0,75), \mathrm{kg}$ e estádio de lactação de 90 dias em leite. Os animais foram distribuídos em um quadrado latino $5 \times 5$ e alojados em baias individuais. Os períodos tiveram uma duração de 15 dias, dos quais 10 de adaptação às dietas e cinco para colheita de dados e amostras. Antes de iniciar o experimento, os animais passaram por um período de adaptação às instalações e manejo de 10 dias.

Nas Tabelas 1 e 2, são apresentadas, respectivamente, a composição químicobromatológica dos ingredientes das dietas, a composição percentual destas e sua composição químico-bromatológica, 
com base na matéria seca. Os tratamentos experimentais consistiram na associação de silagens e fenos com palma forrageira. $\mathrm{O}$ concentrado continha farelo de soja (52\% de PB com base na matéria seca) ureia, sulfato de amônia e mistura mineral.

A cultivar de palma forrageira utilizada foi a gigante (Opuntia fícus-indica Mill), colhida aos dois anos de idade e proveniente da própria estação. A cultivar de leucena (Leucaena leucocephala) utilizado foi a CNPC 846. Foram colhidos ramos com no máximo um centímetro de diâmetro, após o período de frutificação. O feijão guandu (Cajanus cajan (L.) Millsp.) foi obtido de uma propriedade particular, após a colheita das sementes e foi adotado o mesmo critério para confecção do feno de leucena. O capim-elefante (Pennisetum purpureum Scum), Napier, foi fenado após 90 dias do corte de uniformização.

Com relação ao girassol (Helianthus annuus), foi utilizada a cultivar Catissol 01 e foi colhida antes de atingir o ponto ideal para produção de silagem (MELLO, et al. 2006), uma vez que sofria ataque de pássaros. A cultivar de sorgo (Sorghum bicolor) utilizada foi a IPA 467-4-2 (IPA 467). As silagens foram confeccionadas na própria estação. Com relação ao sorgo, a colheita e ensilagem do material foram realizadas quando o grão atingiu o estádio farináceo de maturação. Tanto a planta de sorgo, quanto a de girassol, foram processadas em máquina forrageira e picadas em tamanho de, aproximadamente, $3 \mathrm{~cm}$. As silagens foram acondicionadas em tambores metálicos e armazenadas em local protegido da radiação solar direta e das chuvas.

$\mathrm{O}$ arraçoamento foi realizado duas vezes ao dia, ad libitum, na forma de ração completa. Foram fornecidos 50\% da dieta às $07 \mathrm{~h}$ e $50 \%$ às $16 \mathrm{~h}$, e permitidas sobras entre cinco e dez por cento do total de matéria seca fornecida. Os animais tinham água disponível permanentemente.

Tabela 1. Composição nutricional dos ingredientes das dietas experimentais

\begin{tabular}{lcccrrc}
\hline Item & $\begin{array}{c}\text { Palma } \\
\text { forrageira }\end{array}$ & $\begin{array}{c}\text { Silagem de } \\
\text { sorgo }\end{array}$ & $\begin{array}{c}\text { Silagem de } \\
\text { girassol }\end{array}$ & $\begin{array}{c}\text { Feno de } \\
\text { leucena }\end{array}$ & $\begin{array}{r}\text { Feno de } \\
\text { guandu }\end{array}$ & $\begin{array}{c}\text { Feno de capim- } \\
\text { elefante }\end{array}$ \\
\hline MS (\%) & 9,10 & 29,61 & 21,34 & 86,61 & 88,56 & 87,71 \\
MO $^{1}$ & 87,43 & 92,11 & 86,44 & 92,90 & 94,91 & 88,40 \\
MM & 12,57 & 7,89 & 13,56 & 7,10 & 5,09 & 11,60 \\
PB $^{1}$ & 4,92 & 5,34 & 9,12 & 11,69 & 9,32 & 5,58 \\
EE $^{1}$ & 2,17 & 3,37 & 9,67 & 2,39 & 2,71 & 1,74 \\
CHT $^{1}$ & 81,92 & 84,14 & 67,71 & 79,17 & 83,02 & 82,27 \\
FDNcp $^{1}$ & 31,87 & 64,98 & 49,44 & 66,40 & 69,87 & 77,08 \\
CNFcp & 50,05 & 19,16 & 18,27 & 12,77 & 13,16 & 5,19 \\
PIDN $^{1}$ & 0,20 & 0,42 & 0,46 & 1,08 & 0,60 & 0,20 \\
FDA $^{1}$ & 20,38 & 41,52 & 42,37 & 51,53 & 55,04 & 54,96 \\
LIG $^{1}$ & 3,35 & 8,26 & 9,32 & 17,90 & 15,42 & 12,50 \\
\hline
\end{tabular}

$\mathrm{MS}$ = matéria seca; $\mathrm{MO}=$ matéria orgânica; $\mathrm{MM}=$ matéria mineral; $\mathrm{PB}=$ proteína bruta; $\mathrm{EE}=$ extrato etéreo; $\mathrm{CHT}=$ carboidratos totais; FDNcp = fibra em detergente neutro corrigida para proteína; $\mathrm{CNFcp}=$ carboidratos não fibrosos corrigido para proteína; PIDN = proteína insolúvel em detergente neutro; FDA = fibra em detergente ácido; LIG = lignina.

$1=\% \mathrm{MS}$. 
Rev. Bras. Saúde Prod. Anim., Salvador, v.13, n.3, p.745-754 jul./set., 2012 http://www.rbspa.ufba.br ISSN 15199940

Tabela 2. Percentual de ingredientes e composição nutricional das dietas

\begin{tabular}{|c|c|c|c|c|c|}
\hline \multirow[b]{2}{*}{ Item } & \multicolumn{5}{|c|}{ Tratamentos (\% na MS total) } \\
\hline & $\begin{array}{l}\text { Silagem de } \\
\text { sorgo }\end{array}$ & $\begin{array}{c}\text { Silagem de } \\
\text { girassol }\end{array}$ & $\begin{array}{l}\text { Feno de } \\
\text { leucena }\end{array}$ & $\begin{array}{l}\text { Feno de } \\
\text { guandu }\end{array}$ & $\begin{array}{l}\text { Feno de capim- } \\
\text { elefante }\end{array}$ \\
\hline Palma forrageira & 59,0 & 62,0 & 63,0 & 61,0 & 60,0 \\
\hline Silagem de sorgo & 34,4 & - & - & - & - \\
\hline Silagem de girassol & - & 34,0 & - & - & - \\
\hline Feno de leucena & - & - & 33,7 & - & - \\
\hline Feno de uandu & - & - & - & 35,0 & - \\
\hline Feno de capim-elefante & - & - & - & - & 33,9 \\
\hline Ureia + sulfato de amônio & 1,7 & 1,7 & 1,7 & 1,7 & 1,7 \\
\hline Mistura mineral & 1,6 & 1,6 & 1,6 & 1,6 & 1,6 \\
\hline \multirow[t]{2}{*}{ Farelo de soja } & 3,3 & 0,7 & 0,0 & 0,6 & 2,8 \\
\hline & \multicolumn{5}{|c|}{ Composição Química } \\
\hline Matéria seca (\%) & 13,0 & 11,8 & 13,6 & 14,0 & 14,2 \\
\hline Matéria orgânica ${ }^{1}$ & 86,3 & 84,2 & 86,4 & 87,1 & 85,0 \\
\hline Matéria mineralM ${ }^{1}$ & 13,7 & 15,8 & 13,6 & 12,9 & 15,0 \\
\hline Proteína bruta ${ }^{1}$ & 11,1 & 11,2 & 11,8 & 11,4 & 11,1 \\
\hline Extrato etéreo $^{1}$ & 2,5 & 4,6 & 2,2 & 1,3 & 1,3 \\
\hline Carboidratos totais ${ }^{1}$ & 72,7 & 68,4 & 72,4 & 74,4 & 72,6 \\
\hline Carboidratos não fibrososcp ${ }^{1}$ & 31,0 & 31,8 & 30,0 & 30,5 & 27,0 \\
\hline Fibra em detergente neutrocp ${ }^{1}$ & 41,6 & 36,7 & 42,5 & 44,0 & 45,6 \\
\hline Fibra em detergente ácido ${ }^{1}$ & 26,5 & 27,1 & 30,2 & 31,7 & 31,0 \\
\hline Lignina $^{1}$ & 4,9 & 5,3 & 8,1 & 7,4 & 6,3 \\
\hline
\end{tabular}

As vacas foram ordenhadas, manualmente, duas vezes ao dia, às 05:30h e às $14: 30 \mathrm{~h}$ e as produções individualmente registradas. As pesagens dos animais ocorreram ao início e ao término de cada período experimental.

Durante o período de coleta, amostras de alimentos e sobras foram coletadas diariamente. O consumo foi ajustado, através de pesagens de alimentos e sobras, toda manhã antes da primeira refeição. No final do experimento, foram feitas amostras compostas por animal e por período, as quais foram moídas em moinho com crivo de $1 \mathrm{~mm}$ de diâmetro e, posteriormente, submetidas à análise bromatológica no Laboratório de Nutrição Animal do Departamento de Zootecnia da Universidade Federal Rural de Pernambuco.

Amostras de leite das ordenhas da manhã e tarde, de cada animal, foram coletadas no $15^{\circ}$ dia de cada período experimental, acondicionadas em recipiente com conservante "bronopol" e enviadas para o Laboratório de Leite do Departamento de Zootecnia da Universidade Federal Rural de Pernambuco para determinação de proteína, gordura, lactose e sólidos totais. Os teores de gordura, proteína e lactose, foram determinados por meio do equipamento Bentley 2000, por absorção infravermelha, e sólidos totais por soma dos valores dos componentes anteriores (IDF, 1996).

A coleta de fezes foi realizada diretamente da ampola retal dos animais no $10^{\circ}$ e $12^{\circ}$ dias de cada período experimental, pela manhã e à tarde. As fezes foram pré-secas em estufa de ventilação forçada à $55^{\circ} \mathrm{C}$ e posteriormente moídas a uma granulometria de $2 \mathrm{~mm}$. Foram feitas amostras compostas para futuras análises. 
As determinações de matéria seca (MS), proteína bruta $(\mathrm{PB})$ e extrato etéreo $(\mathrm{EE})$ foram efetuadas, segundo metodologia descrita por Silva \& Queiróz (2002). Para determinação das frações fibra em detergente neutro (FDN) e fibra em detergente ácido (FDA), utilizou-se a metodologia recomendada pelo fabricante do aparelho ANKON, com modificação em relação aos sacos, que foram confeccionados com tecido-não-tecido (TNT), com as mesmas dimensões do original.

$\mathrm{O}$ teor de nutrientes digestíveis totais (NDT) foi estimado de acordo com a seguinte equação: $\operatorname{NDT}(\%)=($ Consumo de NDT/Consumo de MS) x 100. Para estimativa dos carboidratos totais (CHT) foi usada a equação: \%CHT = $100-(\% \mathrm{~PB}+\% \mathrm{EE}+\% \mathrm{MM})$, enquanto para estimativa dos carboidratos não fibrosos (CNF) pela diferença entre \%CHT - \%FDNcp e a FDN corrigida para proteína. Para o cálculo dos nutrientes digestíveis totais (NDT) foi utilizada a equação proposta por Weiss (1999): NDT $=(\mathrm{PBD}+\mathrm{CNFD}+$ FDNcpD + (EED x 2,25)), na qual PBD, CNFD, FDNpD e EED significam, respectivamente, consumos de $\mathrm{PB}, \mathrm{CNF}$, FDN e EE digestíveis, com a FDN corrigida para proteína.

A eficiência alimentar foi calculada para cada vaca, dividiu-se a produção média de leite corrigida para $4 \%$ de gordura, pela ingestão média de MS, por animal, em cada período experimental. A produção do leite para $4 \%$ de gordura (LCG 4\%) foi realizada segundo o NRC (2001), empregando-se a equação: LCG $4 \%=(0,4 \times \mathrm{kg}$ leite $)+(15 \times \mathrm{kg}$ de gordura do leite).

A estimativa de produção de matéria seca fecal foi realizada por meio do indicador interno, fibra em detergente ácido indigestível (FDAi). Alíquotas de $1,0 \mathrm{~g}$ de fenos, silagens, palma e farelo de soja e $0,5 \mathrm{~g}$ de sobras e fezes foram acondicionadas em sacos de TNT $\left(100 \mathrm{~g} / \mathrm{m}^{2}\right)$ e incubadas no rúmen de um búfalo, por um período de 288 horas (CASALI et al., 2008). O material remanescente da incubação foi levado ao Laboratório de Nutrição Animal do Departamento de Zootecnia, lavado em água corrente, até o total clareamento da água, feito o mesmo procedimento para determinação de FDA descrito anteriormente. Imediatamente foi levado à estufa de ventilação forçada a $65^{\circ} \mathrm{C}$, por três dias, e logo após em estufa de $105^{\circ} \mathrm{C}$ por 1 hora, retirados acondicionados em dessecador e pesados e o resíduo obtido considerado como FDAi.

$\mathrm{O}$ delineamento experimental foi $\mathrm{o}$ quadrado latino. Os dados foram submetidos à análise de variância, por meio do programa SAEG (Sistema de Análises Estatísticas e Genéticas) da Universidade Federal de Viçosa (UFV, 2001). Para comparação das médias foi utilizado o teste de Tukey com nível de significância de $1 \%$. O seguinte modelo foi utilizado nas análises:

$\mathrm{y}_{\mathrm{ijk}}=\mu+\mathrm{T}_{\mathrm{i}}+\mathrm{P}_{\mathrm{j}}+\mathrm{A}_{\mathrm{k}}+\mathrm{e}_{\mathrm{ijk}}$ no qual:

$\mu$ é a média do experimento;

$\mathrm{T}_{\mathrm{i}}$ é o efeito do tratamento $\mathrm{i}$;

$P_{\mathrm{j}}$ é o efeito do período $\mathrm{j}$;

$\mathrm{A}_{\mathrm{k}}$ é o efeito do animal k;

$\mathrm{e}_{\mathrm{ijk}}$ é o erro experimental;

sendo $\mathrm{i}, \mathrm{j}, \mathrm{k}=1,2,3,4,5$.

\section{RESULTADOS}

As dietas experimentais apresentaram níveis semelhantes de proteína bruta, mas houve variação considerável nos teores de matéria seca $(11,8$ a $14,2 \%)$, extrato etéreo (1,3 a 4,6\%) e lignina (4,9 a $8,1 \%)$. Em relação aos teores de carboidratos não fibrosos, apenas a dieta composta por feno de capim-elefante apresentou teor reduzido em relação às 
demais $(27,0 \%)$. Os teores de fibra em detergente neutro e ácido também não foram uniformes entre os tratamentos (Tabela 3).

A silagem de girassol apresentou baixo teor de matéria seca $(21,34 \%)$, o que poderia afetar o consumo desse parâmetro, porém essa resposta não foi observada. Como discutido anteriormente, a colheita foi realizada precocemente em virtude do ataque de pássaros. Borgatti et al. (2005) afirmaram que a principal limitação da conservação da cultura de girassol, pelo processo de ensilagem, é o baixo teor de matéria seca próximo ao momento do corte, em torno de $24 \%$.

Tabela 3. Consumos médios diários de matéria seca (MS), matéria orgânica (MO), proteína bruta $(\mathrm{PB})$, fibra em detergente neutro (FDN), carboidratos totais (CHT), carboidratos não fibrosos (CNF) e nutrientes digestíveis totais (NDT)

\begin{tabular}{|c|c|c|c|c|c|c|}
\hline \multirow[b]{2}{*}{ Consumo } & \multicolumn{5}{|c|}{ Tratamentos } & \multirow{2}{*}{$\begin{array}{l}\mathrm{CV} \\
(\%)\end{array}$} \\
\hline & $\begin{array}{l}\text { Silagem de } \\
\text { sorgo }\end{array}$ & $\begin{array}{c}\text { Silagem de } \\
\text { girassol }\end{array}$ & $\begin{array}{l}\text { Feno de } \\
\text { leucena }\end{array}$ & $\begin{array}{l}\text { Feno de } \\
\text { guandu }\end{array}$ & $\begin{array}{l}\text { Feno de capim- } \\
\text { elefante }\end{array}$ & \\
\hline MS (kg/ dia) & $13,29^{\mathrm{a}}$ & $13,13^{\mathrm{a}}$ & $14,54^{\mathrm{a}}$ & $14,16^{\mathrm{a}}$ & $14,95^{\mathrm{a}}$ & 9,25 \\
\hline $\mathrm{MS}(\% \mathrm{PV})$ & $2,59^{\mathrm{a}}$ & $2,53^{\mathrm{a}}$ & $2,84^{\mathrm{a}}$ & $2,75^{\mathrm{a}}$ & $2,88^{\mathrm{a}}$ & 3,39 \\
\hline $\operatorname{MS}\left(\mathrm{g} / \mathrm{kg}^{0,75}\right)$ & $122,98^{\mathrm{a}}$ & $120,72^{\mathrm{a}}$ & $134,86^{\mathrm{a}}$ & $130,81^{\mathrm{a}}$ & $137,41^{\mathrm{a}}$ & 8,85 \\
\hline MO (kg/dia) & $11,84^{\mathrm{a}}$ & $11,37^{\mathrm{a}}$ & $12,93^{\mathrm{a}}$ & $12,66^{\mathrm{a}}$ & $13,11^{\mathrm{a}}$ & 9,24 \\
\hline PB (g/dia) & $1,48^{\mathrm{a}}$ & $1,44^{\mathrm{a}}$ & $1,76^{\mathrm{a}}$ & $1,54^{\mathrm{a}}$ & $1,59^{\mathrm{a}}$ & 10,93 \\
\hline $\begin{array}{l}\text { FDNcp } \\
(\mathrm{kg} / \text { dia) }\end{array}$ & $5,17^{\mathrm{ab}}$ & $4,54^{\mathrm{b}}$ & $6,00^{\mathrm{ab}}$ & $6,23^{\mathrm{ab}}$ & $6,47^{\mathrm{a}}$ & 11,28 \\
\hline FDN (\% PV) & $1,01^{\mathrm{ab}}$ & $0,87^{\mathrm{b}}$ & $1,17^{\mathrm{ab}}$ & $1,08^{\mathrm{ab}}$ & $1,25^{\mathrm{a}}$ & 11,15 \\
\hline CHT (kg/dia) & $10,77^{\mathrm{a}}$ & $11,49^{\mathrm{a}}$ & $10,58^{\mathrm{a}}$ & $10,44^{\mathrm{a}}$ & $12,20^{\mathrm{a}}$ & 9,23 \\
\hline $\begin{array}{l}\text { CNFcp } \\
\text { (kg/dia) }\end{array}$ & $5,44^{\mathrm{a}}$ & $5,40^{\mathrm{a}}$ & $5,66^{\mathrm{a}}$ & $5,81^{\mathrm{a}}$ & $5,41^{\mathrm{a}}$ & 8,00 \\
\hline NDT(kg/dia) & $9,00^{\mathrm{a}}$ & $8,36^{\mathrm{a}}$ & $8,79^{\mathrm{a}}$ & $8,87^{\mathrm{a}}$ & $8,73^{\mathrm{a}}$ & 9,60 \\
\hline
\end{tabular}

Médias seguidas por diferentes letras na mesma linha diferem entre si a $1 \%$ pelo Teste de Tukey.

O consumo de MS não foi alterado em função dos diferentes volumosos $(\mathrm{P}>0,01)$. Um fator que poderia ter contribuído para esse comportamento, foi a alta proporção de palma em todos os tratamentos, em torno de $60 \%$, alimento que apresenta alta palatabilidade e digestibilidade. Ademais, como o fornecimento das dietas foi na forma de ração completa, possíveis efeitos negativos dos diferentes volumosos sobre o consumo foram minimizados.

O consumo médio de matéria seca foi de $14,05 \mathrm{~kg} / \mathrm{dia}$, valor próximo ao estimado pelo NRC (2001), que foi de $13,93 \mathrm{~kg} /$ dia para vacas de 516,95 $( \pm 9,84) \mathrm{kg}$ de peso vivo, com produção de $10,6 \mathrm{~kg} / \mathrm{dia}$ de leite com $4 \%$ de gordura, produção média observada no presente trabalho.

As médias referentes aos consumos diários dos nutrientes, bem como os coeficientes de variação em função dos tratamentos são apresentados na Tabela 3. Não foi observada diferença significativa $(\mathrm{P}>0,01)$ para o consumo de matéria seca entre os tratamentos, independentemente da forma expressa.

Os consumos de $\mathrm{MO}, \mathrm{PB}, \mathrm{CHT}, \mathrm{CNF}$ e NDT não diferiram $(\mathrm{P}>0,01)$, de 
modo que apresentaram as médias 12,$38 ; 1,56 ; 11,10 ; 5,54$ e $8,75 \mathrm{~kg} / \mathrm{dia}$, respectivamente, possivelmente, devido à pouca alteração desses componentes na dieta, seguindo o mesmo comportamento do consumo de MS.

No que respeita ao consumo de FDN, foi observado maior consumo $(\mathrm{P}<0,01)$ para o feno de capim-elefante, em relação à silagem de girassol, e valores similares aos demais volumosos.

Os consumos de MO e NDT não diferiram também, possivelmente, devido à pouca alteração destes componentes na dieta, seguindo o mesmo comportamento do consumo de MS. Com relação ao consumo de FDN, a superioridade observada para o feno de capim-elefante em relação à silagem de girassol e similares nos demais tratamentos, pode ser explicada devido ao maior teor de FDN presente no feno de capimelefante em relação à silagem de girassol. O consumo médio de FDN, no presente trabalho, foi de $1,07 \%$ do peso corporal, portanto, abaixo do valor de $1,2 \%$, sugerido pelo NRC (2001) como fator limitante para o consumo de matéria seca de vacas em lactação.

Os dados referentes à digestibilidade aparente dos nutrientes estão apresentados na Tabela 4. A digestibilidade da MS para as silagens de sorgo e de girassol foram superiores $(\mathrm{P}<0,01)$ quando comparada aos fenos.

Tabela 4. Digestibilidades médias da matéria seca (MS), matéria orgânica (MO), proteína bruta (PB), extrato etéreo (EE), fibra em detergente neutro (FDN), carboidratos totais (CHT) e carboidratos não fibrosos (CNF) em função dos tratamentos

\begin{tabular}{|c|c|c|c|c|c|c|}
\hline \multirow[b]{2}{*}{ Itens } & \multicolumn{5}{|c|}{ Tratamentos } & \multirow[b]{2}{*}{$\mathrm{CV}(\%)$} \\
\hline & $\begin{array}{c}\text { Silagem } \\
\text { sorgo }\end{array}$ & $\begin{array}{c}\text { Silagem } \\
\text { girassol }\end{array}$ & $\begin{array}{l}\text { Feno de } \\
\text { leucena }\end{array}$ & $\begin{array}{l}\text { Feno de } \\
\text { guandu }\end{array}$ & $\begin{array}{l}\text { Feno de } \\
\text { elefante }\end{array}$ & \\
\hline MS & $70,26^{\mathrm{a}}$ & $66,55^{\mathrm{ab}}$ & $61,40^{c}$ & $62,79^{\mathrm{bc}}$ & $61,09^{\mathrm{c}}$ & 2,52 \\
\hline MO & $72,85^{\mathrm{a}}$ & $69,17^{\text {ab }}$ & $63,10^{\mathrm{b}}$ & $65,07^{\mathrm{b}}$ & $63,49^{\mathrm{b}}$ & 3,55 \\
\hline PB & $69,47^{\mathrm{a}}$ & $70,53^{\mathrm{a}}$ & $59,41^{\mathrm{a}}$ & $65,52^{\mathrm{a}}$ & $69,20^{\mathrm{a}}$ & 7,13 \\
\hline $\mathrm{EE}$ & $71,61^{\mathrm{a}}$ & $67,82^{\mathrm{a}}$ & $46,26^{\mathrm{a}}$ & $45,15^{\mathrm{a}}$ & $43,63^{\mathrm{a}}$ & 19,08 \\
\hline FDN & $57,34^{\mathrm{a}}$ & $41,29^{\mathrm{ab}}$ & $40,22^{\mathrm{ab}}$ & $32,57^{\mathrm{b}}$ & $42,65^{\mathrm{ab}}$ & 18,43 \\
\hline CHT & $74,80^{\mathrm{a}}$ & $70,83^{\mathrm{a}}$ & $66,45^{\mathrm{a}}$ & $67,35^{\mathrm{a}}$ & $65,03^{\mathrm{a}}$ & 4,10 \\
\hline $\mathrm{CNF}$ & $90,07^{\mathrm{a}}$ & $93,65^{\mathrm{a}}$ & $92,74^{\mathrm{a}}$ & $97,93^{\mathrm{a}}$ & $91,15^{\mathrm{a}}$ & 3,75 \\
\hline
\end{tabular}

Médias seguidas por diferentes letras na mesma linha diferem entre si a $1 \%$ pelo Teste de Tukey

Essa diferença pode ser justificada em parte pelos maiores níveis de lignina e fibra em detergente ácido, componentes tipicamente relacionados com a digestibilidade, presentes nos fenos (Tabelas 1 e 2). A lignina é um constituinte da célula vegetal de baixa ou nula digestibilidade, que exerce influência sobre a digestibilidade da MS, da fibra, da celulose e hemicelulose. Além disso, é considerada o principal fator limitante da digestibilidade em forragens
(LAUNCHBAUGH et al., 2001) e sua proporção aumenta à medida que a planta amadurece, diminuindo a porção mais digestível, consequentemente, a disponibilidade de energia para o animal. Vale ressaltar que os fenos de leucena e de guandu foram confeccionados quando as plantas já haviam passado do ponto de frutificação e que foram usados também os talos das plantas. Segundo Gama et al. (2009), a lignificação das forragens de leguminosas lenhosas ocorre 
principalmente nas hastes e não nas folhas.

Para a digestibilidade da PB e CNF, não foi observado diferença entre os tratamentos, cujas médias foram 66,82 e $93,10 \%$, respectivamente. Já para a digestibilidade do EE, FDN e CHT observa-se, no geral, uma superioridade da associação da silagem de sorgo com a palma comparada a associação com os fenos.

Os resultados relativos ao desempenho produtivo das vacas são apresentados na Tabela 5. Em relação à produção de leite, em $\mathrm{kg} / \mathrm{dia}$, não foi observada diferença significativa $(\mathrm{P}>0,01)$ entre os tratamentos, com média diária de $11,1 \mathrm{~kg}$. No que se refere à produção de leite corrigida para $4 \%$ de gordura, a associação da silagem de girassol com a palma forrageira foi superior $(\mathrm{P}<0,01)$ à associação com os fenos.

Quanto aos teores (\%) e produções (kg/dia) de gordura, proteína e sólidos totais não foram observadas diferenças significativas $(\mathrm{P}>0,01)$ entre os tratamentos. Foram verificadas as respectivas médias diárias de 3,73 e 0,$41 ; 2,93$ e 0,$32 ; 12,16 \%$ e $1,34 \mathrm{~kg} /$ dia.

Tabela 5. Produção de leite (PL), produção de leite corrigido para 4\% gordura (PLCG), e produções $(\mathrm{kg} /$ dia) e teores $(\%)$ de gordura $(\mathrm{G})$, proteína $(\mathrm{P})$ e sólidos totais $(\mathrm{ST})$

\begin{tabular}{|c|c|c|c|c|c|c|}
\hline \multirow[b]{2}{*}{ Itens } & \multicolumn{5}{|c|}{ Tratamentos } & \multirow[b]{2}{*}{$\mathrm{CV}(\%)$} \\
\hline & $\begin{array}{c}\text { Silagem } \\
\text { sorgo }\end{array}$ & $\begin{array}{l}\text { Silagem } \\
\text { girassol }\end{array}$ & $\begin{array}{l}\text { Feno de } \\
\text { leucena }\end{array}$ & $\begin{array}{l}\text { Feno de } \\
\text { guandu }\end{array}$ & $\begin{array}{l}\text { Feno de } \\
\text { elefante }\end{array}$ & \\
\hline PL (kg/dia) & $10,67^{\mathrm{a}}$ & $12,24^{\mathrm{a}}$ & $11,24^{\mathrm{a}}$ & $10,34^{\mathrm{a}}$ & $10,92^{\mathrm{a}}$ & 7,26 \\
\hline PLCG (kg/dia) & $10,71^{\mathrm{ab}}$ & $11,80^{\mathrm{a}}$ & $10,28^{\mathrm{b}}$ & $9,85^{\mathrm{b}}$ & $10,40^{\mathrm{b}}$ & 4,69 \\
\hline $\mathrm{G}(\%)$ & $4,03^{\mathrm{a}}$ & $3,75^{\mathrm{a}}$ & $3,44^{\mathrm{a}}$ & $3,70^{\mathrm{a}}$ & $3,72^{\mathrm{a}}$ & 11,58 \\
\hline G (kg/dia) & $0,42^{\mathrm{a}}$ & $0,46^{\mathrm{a}}$ & $0,39^{\mathrm{a}}$ & $0,38^{\mathrm{a}}$ & $0,40^{\mathrm{a}}$ & 7,72 \\
\hline $\mathrm{P}(\%)$ & $3,14^{\mathrm{a}}$ & $2,67^{\mathrm{a}}$ & $2,88^{\mathrm{a}}$ & $3,00^{\mathrm{a}}$ & $2,97^{\mathrm{a}}$ & 6,73 \\
\hline $\mathrm{P}$ (kg/dia) & $0,33^{\mathrm{a}}$ & $0,32^{\mathrm{a}}$ & $0,32^{\mathrm{a}}$ & $0,31^{\mathrm{a}}$ & $0,32^{\mathrm{a}}$ & 8,15 \\
\hline ST $(\%)$ & $12,81^{\mathrm{a}}$ & $11,91^{\mathrm{a}}$ & $11,85^{\mathrm{a}}$ & $12,12^{\mathrm{a}}$ & $12,10^{\mathrm{a}}$ & 3,63 \\
\hline ST (kg/dia) & $1,36^{\mathrm{a}}$ & $1,45^{\mathrm{a}}$ & $1,33^{\mathrm{a}}$ & $1,25^{\mathrm{a}}$ & $1,31^{\mathrm{a}}$ & 6,06 \\
\hline
\end{tabular}

A associação da silagem de girassol com palma promoveu uma maior produção de leite, corrigida, provavelmente, devido ao maior consumo de extrato etéreo acompanhado pela maior digestibilidade da matéria seca e da matéria orgânica (Tabela 4). Segundo Mello et al. (2006), a silagem de girassol possui elevado teor de extrato etéreo, o que pode ser considerado fator positivo, haja vista a maior densidade energética dos lipídios em relação à de carboidratos e sua melhor eficiência de utilização da energia, seja pela economia de energia na síntese de ácidos graxos, seja pela menor produção de calor (incremento calórico).

Os níveis médios de FDN e CNF verificados foram 407,5 e $352,8(\mathrm{~g} / \mathrm{kg}$ de MS), respectivamente. O NRC (2001) propôs, para dietas de vacas em lactação, teor mínimo de $250 \mathrm{~g} / \mathrm{kg}$ por $\mathrm{Kg} / \mathrm{MS}$ de FDN da matéria seca total e que $75 \%$ dessa FDN (19\% da MS) seja oriunda de volumosos. Da mesma forma o NRC (2001) sustenta que o valor máximo de CNF seja de $44 \%$, no intuito de favorecer a fermentação 
ruminal e evitar a depressão da gordura do leite. Nesse sentido, pode-se verificar que, em todos os tratamentos, os valores ficaram dentro da recomendação sugerida pelo NCR (1989). Por outro lado, os baixos valores de CNF verificados devem explicar as baixas médias para a proteína do leite $(2,93 \%)$.

Em dietas com aproximadamente $60 \%$ de palma e $35 \%$ de volumoso, a utilização da silagem de girassol, silagem de sorgo, feno de leucena, feno de guandu e feno de capim-elefante, a quantidade de concentrado utilizada foi mínima, aspecto de grande relevância uma vez que a ração concentrada representa a maior parte dos custos com alimentação dos rebanhos.

A associação da palma forrageira com a silagem de girassol apresentou maior produção de leite corrigida para gordura em relação aos fenos. No entanto, a escolha do volumoso vai depender da disponibilidade, condições climáticas e sistema de cultivo na região.

\section{REFERÊNCIAS}

ANDRADE, D.K.B.; FERREIRA, M.A.; VÉRAS, A.S.C.; WANDERLEY, W.L.; SILVA, L.E.; CARVALHO, F.F.R.; ALVES, K.S.; MELO, W.S. Digestibilidade e absorção aparentes em vacas da raça Holandesa alimentadas com palma forrageira (Opuntia fícus-indica Mill) em substituição à silagem de sorgo (Sorghum bicolor (L,) Moench).

Revista Brasileira de Zootecnia, v.31, n, 5, p.2088-2097, 2002.

BATISTA, A.M.V.; MUSTAFA, A.F.; TIM, M.; WANG. Y.; SOITA, H.; MCKINNON, J.J. Effects of variety on chemical composition, in situ nutrient disappearance and in vitro gas production of spinelless cacti. Journal of the Science of Food and

Agriculture, v.83, n.2, p.440-445, 2003.

BORGATTI, L.M.O.; RODRIGUES, P.H.M; ALMEIDA, T.F.; MEYER, M. Valor nutritivo da silagem de girassol inoculada com bactérias acido-láticas. Revista Brasileira de Zootecnia, v.34, n.1, p.340-344, 2005.

CASALI, A.O.; DETMANN, E.; VALADARES FILHO, S.C.; PEREIRA, J.C.; HENRIQUES, L.T.; FREITAS. S.G.; PAULINO, M.F. Influência do tempo de incubação e do tamanho de partículas sobre os teores de compostos indigestíveis em alimentos e fezes bovinas obtidos por procedimentos in situ. Revista

Brasileira de Zootecnia,v.37, n.2 , p.335-342, 2008.

FERREIRA, M.A.; SILVA, F.M.; BISPO, S.V.; AZEVEDO, M. Estratégias na suplementação de vacas leiteiras no semi-árido do Brasil.

Revista Brasileira de Zootecnia, v.38, p.322-329, 2009. Supl. especial.

GAMA, T.C.M.; ZAGO, V.C.P.; N.; M.L.F.; LAURA, V.A.; VOLPE, E.; MORAIS, M.G. Composição bromatológica, digestibilidade in vitro e produção de biomassa de leguminosas forrageiras lenhosas cultivadas em solo arenoso. Revista Brasileira de Saúde e Produção Animal [Online], v.10, n.3, p 560-572, 2009.

INTERNATIONAL DAIRY FEDERATION - IDF. Milk: determination of milk fat, protein and lactose content. Guide for the operation of mid-infra-red instruments. Brussells, 1996. p.12.

LAUNCHBAUGH, K.L.; PROVENZA, F.D.; ROPP, J. Understanding herbivore 
Rev. Bras. Saúde Prod. Anim., Salvador, v.13, n.3, p.745-754 jul./set., 2012 http://www.rbspa.ufba.br ISSN 15199940

response to anti-quality factors in forages. Journal of Range

Management, v.54, n.2, p.431-440, 2001.

MELLO, R.; NÖRNBERG, J.L.; QUEIROZ, A.C.; MIRANDA, E.N.; MAGALHÃES, A.L.R.; DAVID, D.B.; SARMENTO, J.L.R. Composição química, digestibilidade e cinética de degradação ruminal das silagens de híbridos de girassol em diferentes épocas de semeadura. Revista

Brasileira de Zootecnia, v. 35, n.4, p.1523-1534, 2006.

MELLO, R.; NÖRNBERG, J.L.; RESTLE, J.A.C.; NEUMANN, M.; QUEIROZ, A.C.; DAVID, D.B.; SARMENTO, J.L.R.; COSTA, P.B.; MAGALHÃES, A.L.R.; DAVID, D.B. Características fenológicas, produtivas e qualitativas de híbridos de girassol em diferentes épocas de semeadura para produção de silagem. Revista Brasileira de Zootecnia, v.35, n.3, p.672-682, 2006.

MENDIETA-ARAICA, B.; SPÖRNDLY, R.; REYES-SÁNCHEZ N.; SPÖRNDLY, E. Moringa (Moringa oleifera) leaf meal as a source of protein in locally produced concentrates for dairy cows fed low protein diets in tropical areas. Livestock Science, v.137, n. 1-3, p. 10-17, 2011.
NATIONAL RESEARCH COUNCILNRC. Nutrient requeriments of the dairy cattle. 7.ed. Washigton: D.C.: National Academy Press, 2001. 381p.

SILVA, D.J.; QUEIROZ, A.C. Análise de alimentos: métodos químicos e biológicos. 3.ed. Viçosa: Universidade Federal de Viçosa, 2002. 253p.

SOSA, M.Y.; BRASIL, L.H.A.; FERREIRA, M.A.; VÉRAS, A.S.C.; LIMA, L. E.; PESSOA, R.A.S.; MELO, A.A.S.; LIMA, R.M.B.; AZEVEDO, M.; SILVA, A.É. V.N.; HAYES, G.A. Diferentes formas de fornecimento de dietas à base de palma forrageira e comportamento ingestivo de vacas da raça holandesa em lactação. Acta

Scientiarum Animal Science, v.27, n.2, p.261-268, 2004.

UNIVERSIDADE FEDERAL DE VIÇOSA - UFV. SAEG - Sistema de Análises Estatísticas e Genéticas. Versão 8.0, Viçosa, MG, 2001. 150p.

WEISS, W.P. Energy prediction equations for ruminant feeds. In: CORNELL NUTRITION CONFERENCE FOR FEED MANUFACTURERS, 61., 1999, Ithaca. Proceedings... Ithaca: Cornell University, 1999. p.176-185.

Data de recebimento: 12/10/2011

Data de aprovação: 27/05/2012 